\title{
Misdiagnosis of Epileptic Seizures as Manifestations of Psychiatric Illnesses
}

\author{
Seyed M. Mirsattari, Teneille E. Gofton, Derek J. Chong
}

\begin{abstract}
Background: Epileptic seizures may be misdiagnosed if they manifest as psychiatric symptoms or seizures occur in patients with known psychiatric illness. Methods: We present clinical profiles of six patients with epilepsy (three male, mean age $39 \pm$ 12 years) that presented with prominent psychiatric symptoms. Results: Two patients had pre-existing psychiatric illnesses. Three patients were initially diagnosed with panic attacks, two with psychosis, and one with schizophrenia. Five patients had temporal lobe epilepsy (TLE) while the sixth patient was subsequently found to have absence status epilepticus (SE). Cranial computed tomogram (CT) including contrast study was unremarkable in five patients and showed post-traumatic changes in one patient. Cranial magnetic resonance imaging (MRI) revealed dysembryoplastic neuroepithelial tumour (DNET) in one patient, cavernous hemangioma in one, and post-traumatic changes plus bilateral mesial temporal sclerosis in another patient but it was normal in two TLE patients. Routine electroencephalography (EEG) revealed absence SE in one patient but it was non-diagnostic in the TLE patients. Video-EEG telemetry in the epilepsy monitoring unit (EMU) was necessary to establish the diagnosis in four TLE patients. None of the patients responded to medications aimed at treating psychiatric symptoms alone. Two patients required surgery while the other four required treatment with anti-epileptic drugs. All the patients had favorable response to the treatment of their epilepsy. Conclusions: This case series illustrates that epileptic patients may experience non-convulsive seizures that might be mistaken as primary psychiatric illnesses. In this subset of patients, evaluation by an epileptologist, MRI of the brain, and/or video-EEG telemetry in an EMU was necessary to confirm the diagnosis of epilepsy if routine EEGs and cranial CT are normal.
\end{abstract}

RÉSUMÉ: Le diagnostic de crises épileptiques considérées à tort comme des manifestations de maladies psychiatriques. Contexte : Un diagnostic erroné peut être posé si des symptômes psychiatriques sont la manifestation de crises épileptiques ou si des patients atteints de maladies psychiatriques connues présentent des crises épileptiques. Méthode : Nous présentons le profil clinique de 6 patients atteints d'épilepsie, soit 3 hommes et 3 femmes dont l'âge moyen était de $39 \pm 12$ ans, qui ont consulté pour des symptômes psychiatriques évidents. Résultats : Deux patients avaient des maladies psychiatriques préexistantes. Un diagnostic d'attaques de panique a été posé initialement chez 3 patients, un diagnostic de psychose chez 2 et un diagnostic de schizophrénie chez 1. Cinq patients avaient une épilepsie temporale (ET) et un diagnostic d'état de mal épileptique non convulsif a été posé éventuellement chez le 6e patient. Chez 5 patients, la tomodensitométrie cérébrale avec agent de contraste n'a rien révélé, alors que chez le 6e patient cet examen a révélé la présence de changements post-traumatiques. L'IRM cérébrale a révélé la présence d'une tumeur neuroépithéliale dysembryoplasique (TNED) chez un patient, un hémangiome caverneux chez un patient et des changements post-traumatiques ainsi qu'une sclérose mésiotemporale bilatérale chez un autre patient. Cet examen était normal chez 2 patients atteints d'ET. On a dû avoir recours à la vidéo/télémétrie EEG au cours de la surveillance de l'épilepsie à l'unité de surveillance continue de l'épilepsie pour établir le diagnostic d'ET chez 4 patients. Aucun des patients n'a répondu aux médicaments ciblant seulement les symptômes psychiatriques. Deux patients ont dû subir une chirurgie alors que les 4 autres ont été traités au moyen de médicaments antiépileptiques. Tous les patients ont bien répondu au traitement de leur épilepsie. Conclusions : Cette série de cas illustre le fait que des patients épileptiques peuvent présenter des crises non-convulsives et qu'un diagnostic erroné de maladie psychiatrique primaire peut alors être posé à tort. Chez ce sous-groupe de patients, une évaluation par un épileptologue, l'IRM du cerveau et/ou la vidéo/télémétrie EEG dans une unité de surveillance continue de l'épilepsie peut être requise pour confirmer le diagnostic d'épilepsie si les EEG de routine et la tomodensitométrie cérébrale sont normaux.

Can. J. Neurol. Sci. 2011; 38: 487-493

It has been well known that epileptic seizures can be mistaken for psychiatric illnesses such as anxiety or panic attacks $^{1}$, but epileptic seizures can also be mistaken for other psychiatric illnesses. The semiology of certain seizures may appear to fulfill the diagnostic criteria for schizophrenia, brief psychotic disorder, anxiety disorder with panic attacks, and even Alzheimer's dementia as set out by the fourth edition, text revision, of The Diagnostic and Statistical Manual of Mental Disorders (DSM-IV-TR) ${ }^{2}$. Seizure mimicry can be so convincing that a seizure disorder may not be considered, especially if there are no convulsive features or if routine electroencephalography
(EEG) is not diagnostic of epileptic activity. The fact that epilepsy and psychiatric illness may coexist in one patient further complicates the diagnosis of epilepsy. Misdiagnoses of

From the Departments of Clinical Neurological Sciences (SMM, TEG), Medical Biophysics (SMM), Medical Imaging (SMM), Psychology (SMM), The University of Western Ontario, London, Ontario, Canada; Comprehensive Epilepsy Centre (DJC), Columbia University Medical Center, New York, NY, USA.

Received SePtember 21, 2010. Final Revisions Submitted January 17, 2011. Correspondence to: Seyed M. Mirsattari, B10-108, London Health Sciences Centre, 339 Windermere Road, London, Ontario, N6A 5A5, Canada. 

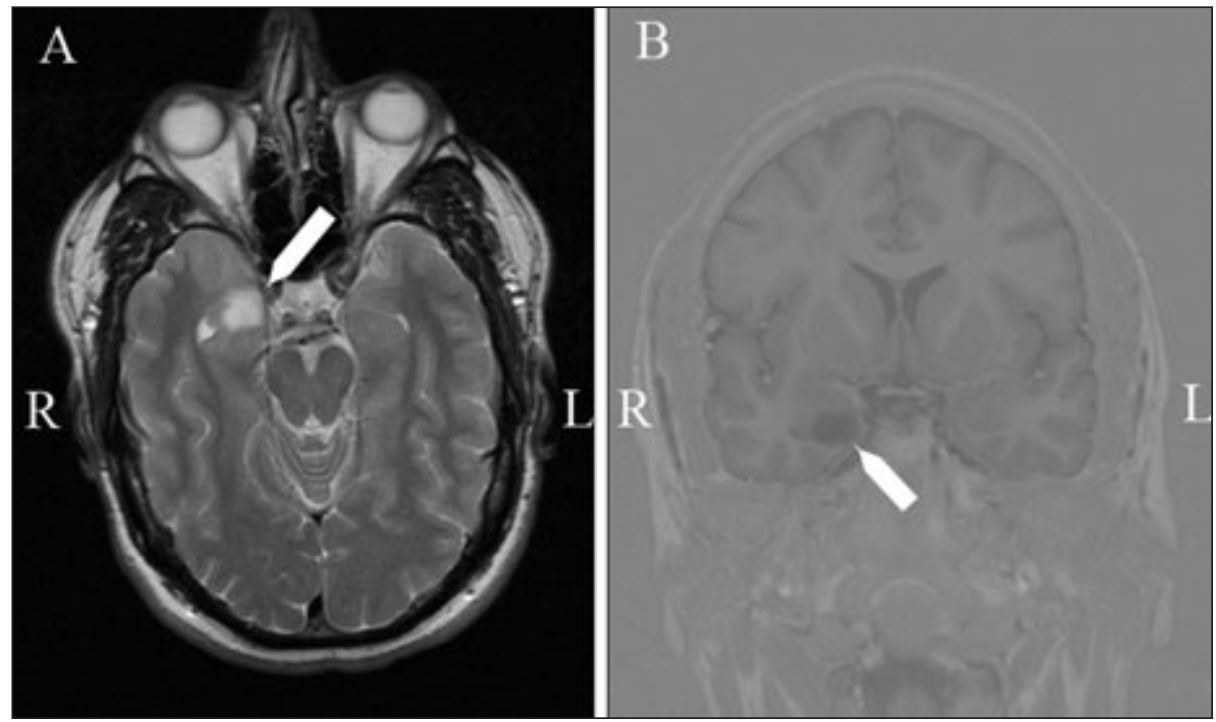

Figure 1: Cranial MRI shows signal abnormality in the right anterior mesial temporal lobe involving the amygdala and anterior hippocampus: axial $T 2(A$, white arrow) and coronal Short T1 Inversion Recovery $(S T I R)(B$, white arrow). It was a non-enhancing lesion which measured $1.5 \mathrm{~cm} x 1.0 \mathrm{~cm}$ and was consistent with a dysembryoplastic neuroepithelial tumour (DNET).

epileptic seizures as psychiatric phenomena might be unavoidable in rare cases unless video-EEG telemetry in an epilepsy monitoring unit (EMU) is utilized. Clinical profiles of six patients are presented. In these patients, epileptic seizures manifested with prominent psychiatric symptoms and were unsuccessfully treated as primary psychiatric disorders. We review the scope and characteristics of psychiatric presentations in epileptic seizures.

\section{Methods}

This is a retrospective chart review of the patients that were seen in the Complex Epilepsy Clinic at London Health Sciences Centre in London, Ontario between 2006 and 2009. The eligible patients were all under the care of one epileptologist (SMM). A systematic review of database was not performed. This study was approved by the Research Ethics Board of the University of Western Ontario.

\section{Case Vignettes}

\section{Case A (Patient 1)}

For six years a 42-year-old farmer experienced paroxysmal episodes of an overwhelming sense of doom, palpitations, pallor, tremulousness and diaphoresis lasting less than 30 seconds, which often occurred upon awakening from sleep. The events occurred in clusters of five to seven spells per two or three weeks. Stress or fatigue would increase the frequency of these events. The patient had lost his daughter in a farming accident one year prior to the onset of his symptoms and had mild anxiety symptoms throughout his life. He was diagnosed with panic attacks. The man's medical and family history was otherwise unremarkable and his neurological examination was normal. $\mathrm{He}$ was treated with paroxetine, sertraline, and nefazodone with poor response and associated weight gain. A seizure disorder was suspected when one day the patient awoke to a blood-soaked pillow, a sore tongue and extreme fatigue.

Further history elicited sense of déjà $v u$ followed by malodorous smell, unusual taste, epigastric sensations, oroalimentary automatisms and occasional sudden erections or flashing lights without postictal features during the panic attacks. Scalp EEG revealed a very mild but intermittent right temporal slowing. Computerized tomography (CT) of the brain with contrast was unremarkable but magnetic resonance imaging (MRI) of the brain showed a non-enhancing right anterior mesial temporal lesion involving the amygdala and anterior hippocampus measuring $1.5 \mathrm{~cm} \times 1.0 \mathrm{~cm}$ (Figure 1). The patient was refractory to phenytoin $500 \mathrm{mg}$ daily with longer lasting spells (i.e. up to two to three minutes) progressing to generalized tonic-clonic seizures (GTCS). Surgical resection of the lesion, a dysembryoplastic neuroepithelial tumour (DNET), resulted in complete resolution of his symptoms without medications at six months of follow-up.

\section{Case B (Patient 5)}

A 55-year-old man with long-standing paranoid schizophrenia developed prolonged withdrawal episodes lasting minutes to hours associated with inactivity, slow speech, open jaw, blank stares, and urinary incontinence. They were followed by gradual recovery to baseline the following day. He rarely experienced mild jerking of his extremities during the episodes. These episodes occurred about twice a week. He used to live independently but he required greater care and frequent visits to the hospital for these spells. He was sent to a retirement home and then a nursing home because of his inability to care for himself during these spells. He was presumed to have an exclusively psychiatric disorder and was treated with daily citalopram $20 \mathrm{mg}$, risperidone $2.5 \mathrm{mg}$, and carbamazepine 800 $\mathrm{mg}$. He otherwise had non-insulin dependent diabetes mellitus and ischemic heart disease. 


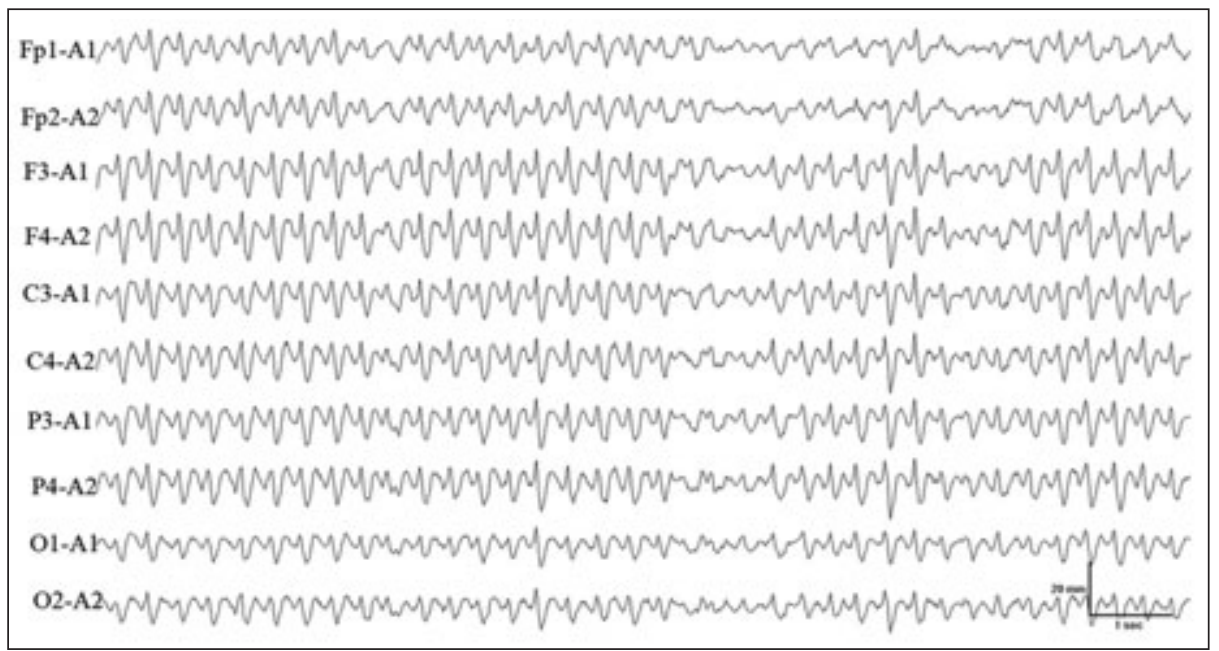

Figure 2: Scalp EEG shows absence status epilepticus with generalized spikes-and-waves at 2.5-3 Hz. Referential recording: sensitivity= $10 \mu v / m m$, $L F F=1 \mathrm{~Hz}, \mathrm{HFF}=70 \mathrm{~Hz}$, notch filter off.

While being assessed, he was completely unresponsive with his eyes fixated on the ceiling and mouth wide open. He intermittently followed commands, focused on faces and smiled appropriately. He exhibited spontaneous and stimulus-induced generalized myoclonus to auditory and visually stimuli. His physical examination was remarkable for mild peri-oral and buccal tremors, positive palmomental reflex on the left, and absent ankle jerks. Scalp EEG revealed absence status epilepticus with generalized slow spike and waves at $2.5 \mathrm{~Hz}$ (Figure 2). He became fully responsive as soon as the epileptiform activities disappeared following administration of 3 $\mathrm{mg}$ of intravenous lorazepam. Carbamazepine was discontinued and he was treated with valproic acid. One year later, the patient had returned to independent living and had no further episodes of unresponsiveness.

\section{RESULTS}

Including the patients described above, six patients with epilepsy (three males, mean age $39 \pm 12$ years) whose seizures manifested with prominent psychiatric symptoms and who were initially unsuccessfully treated for primary psychiatric disorders for a median of $4.5 \pm 2.4$ years (range 1-8 years) were identified (Table 1). A history of generalized convulsive seizures in three patients (Patients 1, 4, and 5), lack of response to psychiatric agents in two patients (Patients 2 and 6) and refusal to take psychiatric therapies in another patient who insisted on being referred to a neurologist by her family physician (Patient 3 ) led to the assessment of these patients in the epilepsy clinic. Two (Patients 1 and 5) had known psychiatric illness and another (Patient 4) had a history of infrequent convulsive seizures. Two (Patients 1 and 5) were institutionalized but none responded to medications aimed at treating psychosis alone. Three patients were initially diagnosed with panic attacks (Patients 1-3), two with psychosis (Patients 4 and 6), and one with paranoid schizophrenia (Patient 5). Five patients were found to have temporal lobe epilepsy (TLE; three right TLE, one left TLE, one bilateral TLE) while another one (Patient 5) presented with absence status epilepticus (SE) in his routine EEG that responded to $3 \mathrm{mg}$ intravenous lorazepam. Detailed history taking at the time of initial neurological evaluation was suspicious for seizures in some of the TLE patients but it was inadequate to clarify the diagnosis. Scalp EEG detected absence SE in one patient (Patient 5) while video-EEG telemetry in an EMU was necessary to confirm the diagnosis in four patients (Patients 2-4 and 6). In the patients requiring EMU admission for diagnosis, the events recorded corresponded with the presenting psychiatric symptoms. Video recordings were of limited diagnostic value on their own except for the brevity and stereotypy of the spells with motionless stares and postical confusion suggestive of seizures. The documented seizure semiologies in Table 1 were the result of serial evaluations and by no means were gathered in the first encounter in the outpatient clinic.

Computed tomography of the brain showed post-traumatic changes in one (Patient 2) but it was normal in the remaining five patients including Patient 1 who underwent a contrast enhanced CT study. Magnetic resonance imaging of the brain detected a DNET in one (Patient 1), cavernous hemangioma in one (Patient 6), and bilateral mesial temporal sclerosis plus post-traumatic encephalomalacia of the right fronto-temporal lobes in one (Patient 2). The MRI was normal in two TLE (Patients 3-4). Patient 5 had presumed idiopathic generalized epilepsy manifesting with absence SE that might have been exacerbated by carbamazepine.

Misdiagnosis led to early management of the symptoms as primary psychiatric illnesses in five patients (Patients 1-2, 4-6) while the symptoms in Patient 3 were overlooked. Two patients were institutionalized for psychosis (Patients 4 and 5). None of the patients responded to medications aimed at treating their psychiatric symptoms alone (Table 2). Surgical removal of the DNET from the right temporal lobe in Patient 1 and right anterior temporal lobectomy in Patient 6 rendered them seizure free. The other patients had good response to anti-epileptic drugs (AEDs). 
Table 1: Clinical profiles of the patients whose epileptic seizures predominantly manifested with psychiatric symptoms

\begin{tabular}{|c|c|c|c|c|c|}
\hline $\begin{array}{l}\text { Patient/age in yrs/ } \\
\text { gender/duration of } \\
\text { symptoms in yrs) }\end{array}$ & Semiology of the events & Frequency & Associated factors & $\begin{array}{l}\text { Psychiatric } \\
\text { diagnosis }\end{array}$ & Psychiatric therapies \\
\hline $1 / 42 / \mathrm{M} / 6$ & $\begin{array}{l}\text { déjà vu followed by a mal-odorous smell, unusual taste in mouth } \\
\text { with indescribable epigastric sensation, oroalimentary; } \\
\text { automatisms and occasional sudden erections or flashing lights } \\
\text { overwhelming sense of doom associated with palpitations, pallor, } \\
\text { tremulousness, and diaphoresis; each event lasted }<30 \text { seconds } \\
\text { without postictal features; they often awoke him up from sleep; } \\
\text { blood-soaked pillow from a bitten tongue followed by extreme } \\
\text { fatigue led to the investigations; one GTC after the diagnosis }\end{array}$ & $\begin{array}{l}\text { clusters of up to seven } \\
\text { spells every two to three } \\
\text { weeks; increased in } \\
\text { frequency by emotional } \\
\text { stress or fatigue }\end{array}$ & $\begin{array}{l}\text { loss of daughter one year } \\
\text { prior to onset of events; } \\
\text { mild untreated anxiety } \\
\text { disorder throughout life }\end{array}$ & $\begin{array}{l}\text { anxiety panic } \\
\text { attacks }\end{array}$ & $\begin{array}{l}\text { paroxetine } \\
\text { sertraline } \\
\text { nefazodone } \\
\text { (caused significant weight } \\
\text { gain) }\end{array}$ \\
\hline $2 / 22 / F / 3.5$ & $\begin{array}{l}\text { type 1: sat motionless on the floor for } 30 \text { seconds associated with } \\
\text { side to side eye movements, amnestic for the events; } \\
\text { type } 2 \text { : staring episodes manifesting with sudden onset fear or } \\
\text { worry associated with déjà-vu or feeling that the room was } \\
\text { closing in on her all lasting }<1 \text { minute followed by feeling } \\
\text { tremulous for } 10-15 \text { minutes }\end{array}$ & $\begin{array}{l}\text { type } 1 \text { events occurred } \\
\text { infrequently for two years } \\
\text { type } 2 \text { events began one } \\
\text { year prior to evaluation, } \\
\text { recurred } 4-6 \text { times per } \\
\text { day on most days }\end{array}$ & $\begin{array}{l}\text { severe closed head injury } 6 \\
\text { months prior to the onset } \\
\text { of symptoms and } 4 \text { years } \\
\text { prior to evaluation }\end{array}$ & $\begin{array}{l}\text { anxiety with } \\
\text { panic attacks }\end{array}$ & $\begin{array}{l}\text { quetiapine } \\
\text { clonazepam } \\
\text { venlafaxine }\end{array}$ \\
\hline $3 / 48 / F / 4$ & $\begin{array}{l}\text { episodes of depersonalization or anxiety without warning that } \\
\text { lasted }<2 \text { minutes and were characterized by feeling weird and } \\
\text { looking at herself from the outside, occasionally accompanied by } \\
\text { fear, panic, fiddling or wringing of the hands and nonsensical } \\
\text { speech; no obvious loss of awareness during them }\end{array}$ & $\begin{array}{l}\text { once every few months at } \\
\text { onset, increased in } \\
\text { frequency to } 3-4 \text { times } \\
\text { per week }\end{array}$ & $\begin{array}{l}\text { complained of worsening } \\
\text { of short-term memory }\end{array}$ & $\begin{array}{l}\text { anxiety with } \\
\text { panic attacks }\end{array}$ & none \\
\hline $4 / 31 / \mathrm{F} / 8$ & $\begin{array}{l}\text { visual hallucinations of spiders, dogs or monsters associated with } \\
\text { intense fear, occasionally had aura of an unusual taste in her } \\
\text { mouth followed by nausea, stated "I want cold water" during } \\
\text { most spells; lasted }<2 \text { minutes; oroalimentary automatisms and } \\
\text { stares accompanied some spells; awareness was rarely impaired } \\
\text { amnesic to the events, postictal confusion and fatigue }\end{array}$ & $\begin{array}{l}1-2 \text { times per month for } 3 \\
\text { years, then increased up } \\
\text { to } 15 \text { events per day on a } \\
\text { daily basis }\end{array}$ & $\begin{array}{l}\text { one generalized tonic } \\
\text { clonic seizure per year at } \\
\text { the ages of } 13,18,19 \text {, and } \\
29, \text { respectively }\end{array}$ & psychosis & $\begin{array}{l}\text { haloperidol } \\
\text { (caused drug-induced } \\
\text { parkinsonism) }\end{array}$ \\
\hline $5 / 55 / \mathrm{M} / 5$ & $\begin{array}{l}\text { episodes of social withdrawal lasting minutes to hours associated } \\
\text { with inactivity, slow speech, open jaw, blank stares, and urinary } \\
\text { incontinence; gradual recovery to baseline the following day } \\
\text { rarely experienced mild jerking of his extremities during episode }\end{array}$ & twice weekly & $\begin{array}{l}\text { loss of ability to care for } \\
\text { self during prolonged } \\
\text { events; required assisted } \\
\text { care living }\end{array}$ & $\begin{array}{l}\text { paranoid } \\
\text { schizophrenia }\end{array}$ & $\begin{array}{l}\text { citalopram } \\
\text { risperidone } \\
\text { carbamazepine }\end{array}$ \\
\hline $6 / 38 / \mathrm{M} / 1$ & $\begin{array}{l}\text { intermittent episodes of deep heavy breathing associated with } \\
\text { uncontrollable thoughts that the DJ on the radio was able to read } \\
\text { his thoughts, automatic phrases, moaning or word salad in some, } \\
\text { shifted his position in chair or in bed during episode, postictal } \\
\text { nausea, getting up and walking around }\end{array}$ & $\begin{array}{l}\text { Weekly events at onset, } \\
\text { rapidly increased to daily } \\
\text { events }\end{array}$ & born 6 weeks prematurely & psychosis & $\begin{array}{l}\text { risperidone } \\
\text { citalopram }\end{array}$ \\
\hline
\end{tabular}

\section{DISCUSSION}

Epilepsy and psychiatric illnesses are both common in the general population ${ }^{3,4}$. Misdiagnosis of epilepsy may have devastating effects on the lives of afflicted individuals, as the alternate diagnosis is often schizophrenia ${ }^{5-11}$, affective disorders ${ }^{12-15}$, or Alzheimer's disease ${ }^{16}$. We describe six patients with epilepsy (five TLE and one with generalized epilepsy) whose seizures manifested predominantly with psychiatric symptoms for several years. Similar to earlier reports $6,10,15,17,18$, they required institutionalization or treatments with psychotropics. The chronicity of their conditions appeared to be a factor impeding the correct diagnosis. We review the scope and common characteristics of such presentations in epilepsy and discuss appropriate investigations that can avoid such misdiagnoses.

\section{Anxiety disorder with panic attacks}

Simple partial seizures in TLE patients could easily meet DSM-IV-TR diagnostic criteria for panic attacks ${ }^{2}$. They usually consist of rising epigastric sensations, overwhelming sense of fear, déjà $v u$, jamais $v u$, depersonalization, palpitations, cold sweats, tremulousness, lightheadedness, or nausea. Only four of these symptoms are required to satisfy the diagnosis of an anxiety disorder with panic attacks as long as they recur unexpectedly and are followed by persistent concerns about their implications or they result in altered behavior for a minimum of one month. If epileptic seizures are not considered, exclusion of 'caused by a general medical condition' is incomplete leading to a psychiatric therapy that would likely fail rather than using AEDs, as was the case in three of our patients in this study. To differentiate anxiety disorder with panic attacks from epilepsy, a detailed seizure history should be elicited because important differentiating features may not be volunteered by the patient. If awareness or memory of the attacks is disrupted, i.e. complex partial seizures (CPSs), automatisms such as lip-smacking, chewing, swallowing, picking or other repetitive movements during the attacks should be inquired about from the witnesses. Postictal confusion and aphasia are also suggestive of epileptic seizures. Other features supportive of TLE over panic attacks include duration (typically, one to two minutes), onset at an age greater than 45 years, history of childhood febrile convulsions ${ }^{14}$, onset of the attacks from sleep ${ }^{19}$, prior brain injury, and lack of response to the treatment of panic disorder. Temporal lobe epilepsy is the most common focal epilepsy in the adults ${ }^{20}$ that can be confused with panic attacks as was demonstrated in three of our patients.

\section{Psychosis}

Psychosis may be a presenting feature of the epileptic seizures or it may be chronic. In addition, some patients may 
Table 2: Investigations and management of the patients whose epileptic seizures predominantly manifested with psychiatric symptoms

\begin{tabular}{|c|c|c|c|c|}
\hline Patient & EEG & MRI & Epileptic seizures & Management \\
\hline 1 & normal routine EEG & $\begin{array}{l}1.5 \mathrm{~cm} \times 1.0 \mathrm{~cm} \text { non-enhancing right } \\
\text { mesial temporal lesion with minimal mass } \\
\text { effect consistent with dysembryoplastic } \\
\text { neuroepithelial tumour (DNET) }\end{array}$ & $\begin{array}{l}\text { complex partial seizures manifesting } \\
\text { with panic attacks and other anxiety } \\
\text { symptoms }\end{array}$ & $\begin{array}{l}\text { medically refractory seizures } \\
\text { no recurrent spells after resection of } \\
\text { the right temporal DNET }\end{array}$ \\
\hline 2 & $\begin{array}{l}\text { independent bitemporal } \\
\text { spikes and seizures in } \\
\text { video-EEG telemetry } \\
\end{array}$ & $\begin{array}{l}\text { bilateral mesial temporal sclerosis } \\
\text { post-traumatic encephalomalacia of the } \\
\text { right temporal and frontal lobes }\end{array}$ & $\begin{array}{l}\text { complex partial seizures manifesting } \\
\text { with panic attacks and other anxiety } \\
\text { symptoms } \pm \text { secondary generalization }\end{array}$ & $\begin{array}{l}\text { phenytoin (gingival hyperplasia) } \\
\text { lamotrigine (well tolerated) } \\
\text { clobazam }\end{array}$ \\
\hline 3 & $\begin{array}{l}\text { right temporal seizures in } \\
\text { video-EEG telemetry }\end{array}$ & normal & $\begin{array}{l}\text { simple and complex partial seizures } \\
\text { manifesting with anxiety symptoms }\end{array}$ & $\begin{array}{l}\text { carbamazepine (not tolerated) } \\
\text { topiramate }\end{array}$ \\
\hline 4 & $\begin{array}{l}\text { right temporal spikes and } \\
\text { seizures in video-EEG } \\
\text { telemetry }\end{array}$ & normal & $\begin{array}{l}\text { simple and complex partial seizures } \\
\text { manifesting with psychosis }\end{array}$ & $\begin{array}{l}\text { carbamazepine } \\
\text { valproic acid }\end{array}$ \\
\hline 5 & $\begin{array}{l}\text { absence status with } 2.5 \mathrm{~Hz} \\
\text { generalized spike and } \\
\text { waves in routine EEG }\end{array}$ & normal & $\begin{array}{l}\text { absence status manifesting with } \\
\text { schizophrenia (likely precipitated by } \\
\text { carbamazepine) }\end{array}$ & $\begin{array}{l}\text { valproic acid } \\
\text { (returned to independent living) }\end{array}$ \\
\hline 6 & $\begin{array}{l}\text { left temporal spikes and } \\
\text { seizures in video-EEG } \\
\text { telemetry }\end{array}$ & $\begin{array}{l}\text { small cavernous hemangioma of the left } \\
\text { temporal neocortex }\end{array}$ & $\begin{array}{l}\text { complex partial seizures manifesting } \\
\text { with psychosis }\end{array}$ & $\begin{array}{l}\text { valproic acid (reduced duration, but } \\
\text { not frequency of the events) } \\
\text { phenytoin } \\
\text { lamotrigine } \\
\text { seizure free for } 6 \text { months after a left } \\
\text { anterior temporal lobectomy }\end{array}$ \\
\hline
\end{tabular}

concurrently have epilepsy and schizophrenia ${ }^{4,21}$. The prevalence of psychoses in patients with epilepsy varies from $2-7 \%$ in the general population up to $20-60 \%$ in psychiatric clinics 22 . Epileptic psychosis may be ictal, interictal, postictal, and may parallel seizure activity or occur as a side-effect of AEDs ${ }^{22}$.

Postictal psychosis is the most common epileptic psychosis which usually follows prolonged seizures, especially GTCSs. Since witnessed GTCSs are easily recognized, there are usually no difficulties in identifying the cause of psychosis in such patients. Postictal psychosis may be misdiagnosed if a lucid interval of one to six days precedes its onset, convulsions go unwitnessed or the epileptic seizure is non-convulsive.

Ictal psychosis may be unrecognized if the seizure manifests exclusively or predominantly with psychosis. Ictal hallucinations may alternate with panic attacks in TLE patients as was the case in our Patient 2. Hallucinations can be of any sensory modality and include sense of smells, tastes, and rising epigastric sensations. Visual phenomena can be simple illusions, such as geometric shapes or colors that are similar to migrainous aura, and localize to the occipital lobe ${ }^{23}$. Illusions such as micropsia, macropsia, and pallinopsia are not uncommon. Auditory phenomena, such as hearing voices and hearing altered or muffled sounds may occur ${ }^{11}$. More developed complex hallucinations with experiential phenomena can follow ${ }^{24}$, including dream sequences, flashbacks and profound affective symptoms. Forced thoughts such as thought withdrawals or thought insertions may occur as complex ictal phenomena ${ }^{8}$. Automatic or semi-responsive speech output during CPSs may be misleading (e.g. Patient 4). The exact symptoms and their timing in each individual depend on the location and spread of the seizures. Specific features of CPSs must be absent before an ictal cause for psychosis is ruled out.
Interictal psychosis can be quite difficult to differentiate from a pure psychiatric cause ${ }^{8}$. Schizophrenia-like psychosis in epilepsy is uncommon but well documented ${ }^{5}$. These patients present similarly to paranoid hallucinatory schizophrenia with a mean latency of about 14.1 years after onset of epilepsy. Factors that may help to distinguish these patients from those having pure schizophrenic processes include high premorbid function, preserved affect, preoccupation with religious, moral or ethical matters ${ }^{7,25}$, and absence of negative symptoms, formal thought disorder or catatonia ${ }^{26,27}$. Earlier age at onset of epilepsy, family history of psychosis, CPSs or GTCSs, and borderline intellectual function are more common among the epilepsy patients that develop interictal psychosis ${ }^{28}$. Despite the lack of randomized, controlled studies to prove it, identification and treatment of epileptic seizures with AEDs in this patient population can improve the outcome of psychosis ${ }^{8}$. Nonetheless, epileptic schizophrenic patients have worse outcome, reflecting the complexity of their symptom complex ${ }^{21}$.

\section{Unexplained cognitive or behavioral decline}

Patient 5 in this study had absence SE that led to his institutionalization. His premorbid psychiatric diagnosis and borderline intelligence likely obscured the importance of his rapid functional decline. Presentations after childhood age, lack of convulsions, longer duration than seconds, and atypical features may all contribute to misdiagnosis of absence seizures even if typical characteristics such as sudden impairment in awareness, motionless blank stares, short durations, or rapid return to baseline are present ${ }^{29}$. Absence SE consists of continuous or nearly continuous absence seizures characterized by constant or fluctuating slowness in behavior and mental status that could vary from mild behavioral changes to apparent 
catatonic attacks, stupor, or coma. Such patients may appear apathetic and lethargic as they can still eat, drink, dress themselves, and follow simple commands ${ }^{30}$. Stereotyped behaviors such as repeated chewing motions, picking at objects, nose rubbing, or subtle myoclonic jerks of the eyelids, cheek, and jaw may occur while stimulus-induced myoclonus may be absent. Absence SE can last days and are rarely accompanied by GTCSs. Atypical absence seizures are more common in patients with developmental delays and can easily be overlooked. An unexplained and significant cognitive or behavioral decline in this population demands further investigations.

\section{Referring to an Epileptologist}

While many patients with epilepsy can be well managed using monotherapy, certain patients will benefit from the expertise of an epileptologist. In the case of patients with epilepsy refractory to a reasonable trial of two different antiepileptic medications or in patients in whom there is diagnostic uncertainty of the nature of their spells, early referral to an epileptologist can be of significant benefit to patients. Not only will an epileptologist have a high degree of experience managing complex patients and unusual seizure semiology, but they will also be more likely to have tools such as a video-EEG monitoring unit and allied health care staff with specific expertise in managing this patient population. Furthermore, patients seen in a specialized epilepsy centre can be considered for potentially curative interventions such as epilepsy surgery.

\section{Discussion Of Case Vignettes And Conclusions}

Case A is an example of complex partial seizures manifesting as panic attacks and other anxiety symptoms. In retrospect, the brief nature of the events with complete resolution in between is suggestive of seizures. Emergence of a generalized tonic-clonic seizure triggered a more seizure oriented history that was further suggestive of seizures. The patient's daughter died in close proximity to the onset of seizures ${ }^{31}$. Such a loss may be associated with the onset of increased anxiety and panic attacks and may contribute to the diagnostic dilemma. Case B describes a patient with absence status manifesting with schizophrenia. The presence of a pre-existing psychiatric disorder contributed to the initial management approach. However, some features suggestive of seizures include the episodic appearance of urinary incontinence, of staring spells and of altered speech with a return to baseline in between. This patient had a prolonged post-ictal period which may render the recognition of the event as being episodic more difficult. In both cases, identification of the clinical behaviors as seizures changed the management approach and improved the clinical course of the patient.

Electroencephalography is generally underutilized in the assessment of patients with neurological disorders. Moreover, routine outpatient EEGs may be inadequate to confirm epilepsy especially if neurological examination and neuroimaging studies are noncontributory. Video-EEG telemetry in an EMU should be considered to avoid misdiagnosis of epilepsy as schizophrenia, affective disorders, or Alzheimer's disease in some cases. While the data for this study was collected retrospectively, which is a limitation of the study, this series suggests that video-EEG telemetry in an EMU should be recommended in patients with refractory and episodic psychiatric symptoms. The EMU monitoring may be required in order to fully differentiate psychiatric manifestations of epileptic seizures from primary psychiatric disorders. Otherwise, exclusion of a 'general medical condition' to meet these diagnostic criteria would be assumed.

These six cases along with the existing literature suggest that misdiagnosis of psychiatric manifestations of epilepsy is likely more common than reported. Episodic manifestations of seizures such as altered respiratory patterns, rising epigastric sensations, a sense of overwhelming fear, brief episodes of behavior with psychotic features or impaired cognition may be misdiagnosed as anxiety disorder with panic attacks, as brief episodes of psychosis or as cognitive impairment. A high degree of suspicion while obtaining neurological/psychiatric history is required in order to investigate and manage patients with epilepsy that present with the above semiology. Finally, epilepsy and psychiatric disorders are not mutually exclusive diagnoses ${ }^{32}$; overlooking either diagnosis in a patient afflicted with both may lead to treatment failures. This study was limited because of its retrospective nature. Large prospective studies are necessary to determine the prevalence and impact of misdiagnosing epileptic seizures as psychiatric disorders.

\section{REFERENCES}

1. Tisher PW, Holzer JC, Greenberg M, Benjamin S, Devinsky O, Bear DM. Psychiatric presentations of epilepsy. Harv Rev Psychiatry. 1993;1(4):219-8.

2. American Psychiatric Association. American Psychiatric Association, Diagnostic and Statistical Manual of Mental Disorders (DSM-IV-TR). Washington, DC: American Psychiatric Press; 2000.

3. Hauser WA, Annegers JF, Kurland LT. Incidence of epilepsy and unprovoked seizures in Rochester, Minnesota: 1935-1984. Epilepsia. 1993;34(3):453-68.

4. Scott KM, Bruffaerts R, Tsang A, et al. Depression-anxiety relationships with chronic physical conditions: results from the World Mental Health Surveys, J Affect Disord. 2007;103(1-3): 113-20.

5. Slater E, Beard AW, Glitheroe E. The schizophrenialike psychoses of epilepsy. Br J Psychiatry. 1963;109:95-150.

6. Adebimpe VR. Complex partial seizures simulating schizophrenia. JAMA. 1977;237:1339-41.

7. Perez MM, Trimble MR. Epileptic psychosis-diagnostic comparison with process schizophrenia. Br J Psychiatry. 1980; 137:245-9

8. Kraft AM, Price TR, Peltier D. Complex partial seizures and schizophrenia. Compr Psychiatry. 1984;25(1):113-24.

9. Minns RA, Valentine D. Psychosis or epilepsy-a diagnostic and management quandary. Seizure. 1994;3 Suppl A:37-9.

10. Swartz CM. Misdiagnosis of schizophrenia for a patient with epilepsy. Psychiatr Serv. 2001;52(1):109.

11. Prueter C, Waberski TD, Norra C, Podoll K. Palinacousis leading to the diagnosis of temporal lobe seizures in a patient with schizophrenia. Seizure. 2002;11(3):198-200.

12. Bowen RC. Differential diagnosis of anxiety disorders. Prog Neuropsychopharmacol Biol Psychiatry. 1983;7(4-6):605-9.

13. Young GB, Chandarana PC, Blume WT, McLachlan RS, Muñoz DG, Girvin JP. Mesial temporal lobe seizures presenting as anxiety disorders. J Neuropsychiatry Clin Neurosci. 1995;7(3): $352-7$.

14. Thompson SA, Duncan JS, Smith SJ. Partial seizures presenting as panic attacks. BMJ. 2000;321(7267):1002-3.

15. Huppertz HJ, Franck P, Korinthenberg R, Schulze-Bonhage A. Recurrent attacks of fear and visual hallucinations in a child. J Child Neurol. 2002;17(3):230-3.

16. Høgh P, Smith SJ, Scahill RI, et al. Epilepsy presenting as AD: neuroimaging, electroclinical features, and response to treatment. Neurology. 2002;58(2):298-301. 
17. Puryear LJ, Kunik ME, Molinari V, Workman RH Jr. Psychiatric manifestations of temporal lobe epilepsy in older adults. J Neuropsychiatry Clin Neurosci. 1995;7(2):235-7.

18. Sazgar M, Carlen PL, Wennberg R. Panic attack semiology in right temporal lobe epilepsy. Epileptic Disord. 2003;5(2):93-100.

19. Krystal JH, Woods SW, Hill CL, Charney DS. Characteristics of panic attack subtypes: assessment of spontaneous panic, situational panic, sleep panic, and limited symptom attacks. Compr Psychiatry. 1991;32(6):474-80.

20. Williamson, PD. Complex partial seizures. In: Engel Jr J, Pedley TA, editors. Epilepsy: a comprehensive textbook. Philadelphia, PA: Lippincott-Raven Publishers; 1997. p. 557-66.

21. Oyebode F, Davison K. Epileptic schizophrenia: clinical features and outcome. Acta Psychiatr Scand. 1989;79(4):327-31.

22. Trimble MR, Schmitz B. The psychoses of epilepsy/schizophrenia. In: Engel Jr J, Pedley TA, editors. Epilepsy: a comprehensive textbook. Philadelphia, PA: Lippincott-Raven Publishers; 1997. p. 2071-81.

23. Martinez JV, Specialli JG. Migraine with visual aura versus occipital epilepsy. Headache. 1997;37(2):113

24. Gloor P, Olivier A, Quesney LF, Andermann F, Horowitz S. The role of the limbic system in experiential phenomena of temporal lobe epilepsy. Ann Neurol. 1982;12(2):129-44.
25. Bear D, Levin K, Blumer D, Chetham D, Ryder J. Interictal behaviour in hospitalised temporal lobe epileptics: relationship to idiopathic psychiatric syndromes. J Neurol Neurosurg Psychiatry. 1982;45(6):481-8.

26. Toone BK, Garralda ME, Ron MA. The psychoses of epilepsy and the functional psychoses: a clinical and phenomenological comparison. Br J Psychiatry. 1982;141:256-61.

27. Perez MM, Trimble MR, Murray NM, Reider I. Epileptic psychosis: an evaluation Of PSE profiles. Br J Psychiatry. 1985; 146:155-63.

28. Adachi N, Matsuura M, Okubo Y, et al. Predictive variables of interictal psychosis in epilepsy. Neurology. 2000;55(9):1310-4.

29. Stefan H, Snead III OC. Absence seizures. In: Engel Jr J, Pedley TA, editors. Epilepsy: a comprehensive textbook. Philadelphia, PA: Lippincott-Raven Publishers; 1997. p. 579-90.

30. Sneed III OC, Dean JC, Penry JK. Absence status epilepticus. In: Engel Jr J, Pedley TA, editors. Epilepsy: a comprehensive textbook. Philadelphia, PA: Lippincott-Raven Publishers; 1997. p. 701-7.

31. Zisook S, Schneider D, Shuchter SR. Anxiety and bereavement. Psychiatr Med. 1190;8(2):83-96.

32. Hermann B, Seidenberg M, Jones J. The neurobehavioral comorbidities of epilepsy: can a natural history be developed? Lancet Neurol. 2008;7(2):151-60. 